\title{
Syndrome of micrencephaly, strio-cerebellar calcifications, and leucodystrophy
}

\author{
R. M. NORMAN AND A. H. TINGEY \\ From the Burden Neuropathological Laboratory, Frenchay Hospital, Bristol
}

A pathological syndrome comprising micrencephaly, symmetrical cerebral calcifications, and patchy demyelination of the cerebral white matter has been delineated on the basis of seven cases reported in the literature (Horanyi-Hechst and Meyer, 1939; Hallervorden, 1950, four cases; Jervis, 1954, two cases). The last two authors considered that the condition was probably the consequence of an encephalitis occurring in early life. The purpose of the present paper is to describe another example of this rare syndrome, to report the chemical findings in the brain, and to give reasons for regarding its pathogenesis as primarily degenerative and not inflammatory. Horanyi-Hechst and Meyer (1939) had originally noted the similarity of the patchy, discontinuous type of myelin loss in their case to that of Pelizaeus-Merzbacher disease and we believe that the condition is best classified as a form of leucodystrophy.

\section{CASE REPORT}

CLINICAL HISTORY This man (K.B.) was an adopted child and his family background is not known. At 13 weeks he had some convulsions but his early progress seemed otherwise normal and he began to walk at 16 months. Speech, however, was delayed until about the age of 5 years and at about this time he had another epileptic attack.

He contracted most of the common infections of childhood without ill effects, but since it became obvious that he was not developing normally he was taken to a children's hospital for investigation. He was then found to be mentally defective and to have spastic paraparesis. Tenotomies and physiotherapy improved his condition and he was able to walk about a mile and to ride a tricycle. At the age of 15 years he was investigated in the Bristol Children's Hospital. He was now considerably undersized and had the appearance of a 'wizened old man' (head circumference $18 \frac{1}{2}$ in.). Mammary overdevelopment was noted. There was a marked tremor in the arms, the legs were spastic and both plantar responses were extensor. Hearing was unaffected and the optic fundi were normal, but it was thought that there was some impairment of vision. The E.E.G. showed 'diffuse generalized organic change with no focal or epileptic characteristics'. Air encephalography showed symmetrical communicating hydrocephalus with considerable cerebral atrophy. No abnormality was found in the cerebrospinal fluid and the Wassermann and Kahn tests were negative. Skull radiological and bone age were normal. His intelligence quotient was estimated at 44 (Wechsler scale).

At the age of 18 years he was admitted to a hospital for mental defectives and here his condition remained stationary until three months before his death when he deteriorated and became incapable of walking. Death took place at the age of 22 years from a respiratory infection.

NECROPSY REPORT (Dr. T. F. Draisey) The body resembled that of a small, wasted boy, and contractures were present at the knees and groins. Pubic hair was scanty and the genitalia were pre-pubertal in size. There was generalized microsplanchnia and the organs appeared healthy except the lungs which showed bronchopneumonia. The vertebral column showed mild kyphoscoliosis. The bones were small and well ossified. Microscopical examination of the liver, spleen, kidney, adrenal, thyroid, and pituitary showed no abnormality.

\section{STUDY OF THE CENTRAL NERVOUS SYSTEM}

MACROSCOPIC The brain was small and weighed 527 g., the cerebellum and brain-stem accounting for only $59 \mathrm{~g}$. The atrophied cerebellum was unduly flat with loose arachnoid covering the ventral surface. The vermis was not especially hypoplastic. The leptomeninges were opaque and thickened in the basal cisterns. The convolutional pattern of the brain, the basal vessels, and the cranial nerves was normal There was great enlargement of the whole ventricular system, the centrum ovale being in the main represented by a narrow rind of tissue. The corpus callosum was also very thin. The basal ganglia appeared small but were in proportion to the brain as a whole. A light brown colour was seen in the globus pallidus and oral part of the substantia nigra. The brain-stem was shrunken, the fourth ventricle was greatly enlarged and the aqueduct wider than usual.

MICROSCOPIC Large celloidin survey sections of the cerebral hemispheres showed no focal or diffuse loss of nerve cells in any part of the cerebral cortex, 
thalamus, or basal ganglia. Except in the stria of Gennari only very scanty myelinated fibres were present in the cerebral cortex, and in most areas the only darkly stained material was a fine granular debris. No microglial proliferation or inflammatory changes were seen.

In the thin central white matter of the hemispheres the myelin staining was generally somewhat reduced in intensity, especially in celloidin sections. Here and there small foci of more severe demyelination were seen (Fig. 1). This patchy loss of myelin sheaths was especially evident in the gyral cores and in the less shrunken frontal and temporal white matter, where well-demarcated myelin islands gave a spotty appearance to the sections (Figs. 2 and 3). The difference between myelinated and demyelinated tissue was also easily seen in the carbol azure preparations, because of the almost complete absence of oligodendroglial nuclei in the areas of myelin loss. Axis cylinders were well preserved in the demyelinated areas (Fig. 4), and there was no evident relationship between these patches and blood vessels. The white matter showed a mild fibrous gliosis which was not confined to areas of demyelination. Sudanophil lipid was scanty but was sometimes seen in the walls of vessels and in a few microglial cells free in the tissues.

Severe generalized poverty of myelin with an occasional suggestion of spotty preservation of fibres was present in all parts of the basal ganglia. Axis cylinders and nerve cells were preserved. In each globus pallidus there was an excess of the iron-containing pigment both in the branched processes of microglial cells and in the vessel walls. A few swollen axis cylinders were present in the form of oval discs, which stained a pale granular blue with carbol azure. The medial part of each putamen contained numerous capillaries encrusted with droplets of calcium, but these were not sufficiently massive to disturb the neuronal architecture (Fig. 5).

A mild diffuse rarefaction of the granular layer of the cerebellum was present throughout most of the cortex and there was occasional droplet calcification of capillaries (Fig. 6). The Purkinje cells showed a patchy reduction in numbers which was associated with empty basket fibres and focal gliosis in the molecular layer. A few Purkinje cells showed dendritic expansions but no axonal swelling or dendritic calcification was seen.

There was severe shrinkage of the central cerebellar white matter, myelination being generally poor and clearly discontinuous in some of the gyral cores (Fig. 7). Fibrous gliosis was considerably denser than in the cerebral hemispheres. The dentate nuclei showed no cell loss. Several veins with calcification of their adventitial and muscular coats, but with no thickening of the intima, were present in the subcortical white matter and in the hila of the dentate nuclei.

The oral part of the red zone of the substantia nigra showed the same increased pigmentation as in the globus pallidus (Fig. 8). Patchy demyelination of the type seen elsewhere was a conspicuous feature of the tegmentum of the midbrain and myelin islands were obvious (Fig. 9). The enlarged aqueduct showed subependymal gliosis and mild granular ependymitis. A few vessels with conspicuous sudanophil lipid in their walls were seen in the cerebral peduncles. A remarkable global shrinkage had occurred in the pons and medulla, and the fourth ventricle was greatly dilated. Myelination was particularly poor in the transverse fibres of the pons and could not be regarded as entirely normal in any part of the brain-stem (Fig. 10). The medullary pyramids were considerably smaller than those of the normal adult, but were not selectively demyelinated. The leptomeninges showed mild fibrosis and no inflammatory changes. The choroid plexuses and the larger cerebral blood vessels were unremarkable.

CHEMISTRY The analytical methods were the same as those described in previous papers (Tingeys 1959; Tingey and Edgar, 1963). The brain had beeț fixed in formol-saline for 17 months. Comparison has been made with the average values obtained from four unfixed normal adult brains examine by similar methods (Table). The white matter showe

\section{TABLE}

VALUES OF CHEMICAL BRAIN CONSTITUENTS ${ }^{1}$

Chemical Constituent Cerebral White Matter Cerebral Cortex

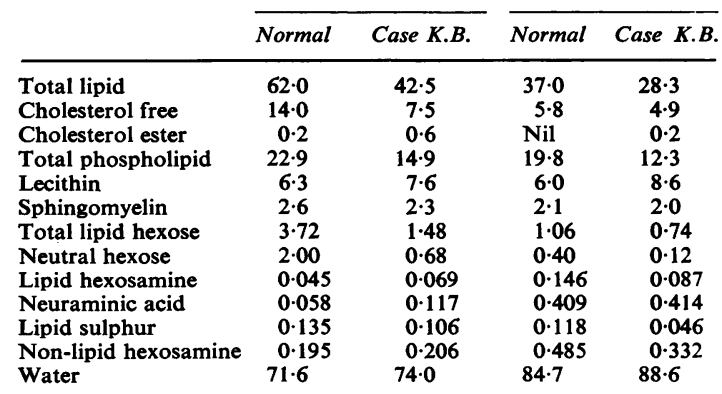

${ }^{1}$ All values (except water) in $\mathrm{g} . / 100 \mathrm{~g}$. of dry tissue

the usual picture of demyelination in so far as there was an unequivocal reduction in total lipid, total lipid hexose, free cholesterol, total phospholipid, and neutral hexose. The raised cholesterol ester suggested an orthochromatic (sudanophil) type of demyelinating process. The sphingomyelin was within the range of variation shown by normal . 


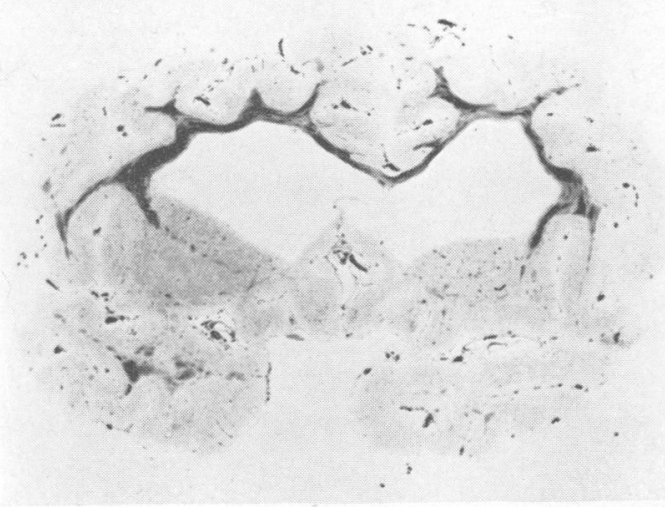

FIG. 1. Coronal section of the micrencephalic brain through the anterior part of the corpus striatum. The central white matter is greatly atrophied and shows patchy demyelination. Heidenhain $\times 0.86$.

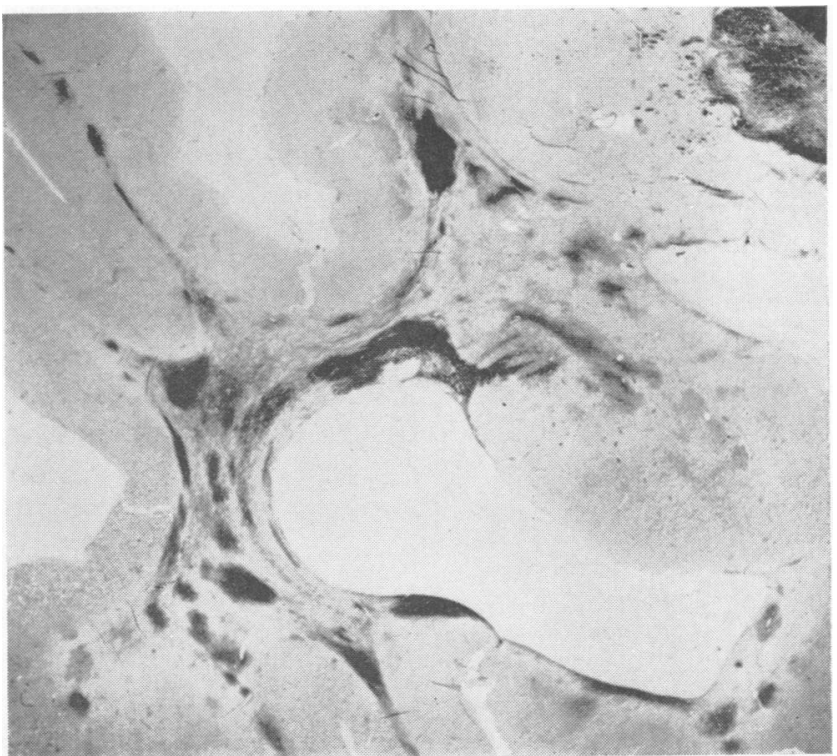

FIG. 2. The white matter of the temporal lobe shows severe demyelination with preserved myelin islands. Frozen. Kultschitsky$\mathrm{Pal} \times 3.3$.

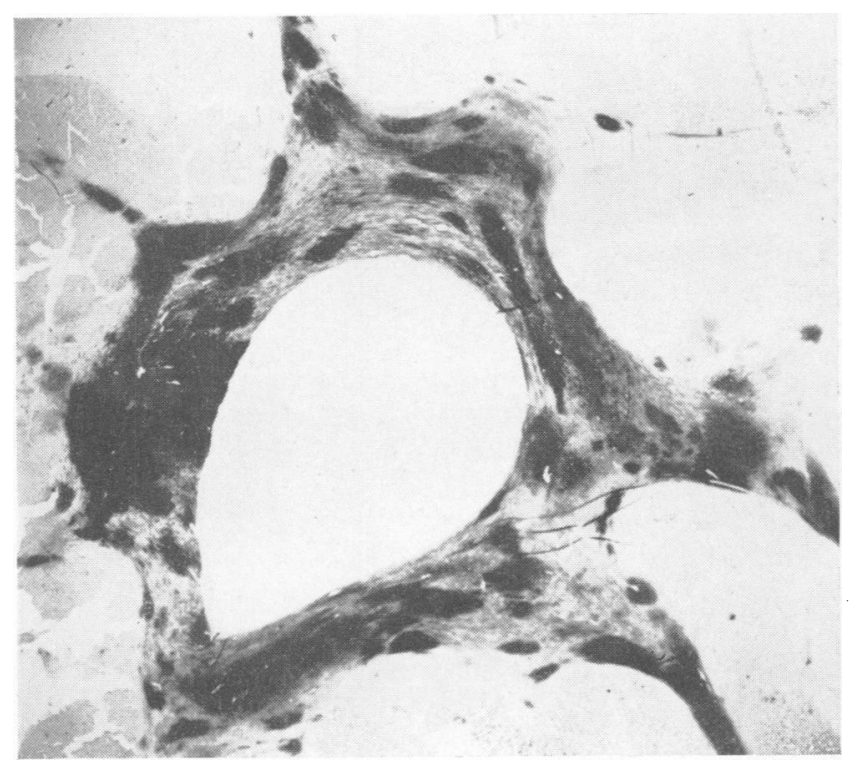

FIG. 3. Frontal pole showing spotty demyelination. Frozen. Kultschitsky-Pal $\times 3.3$.

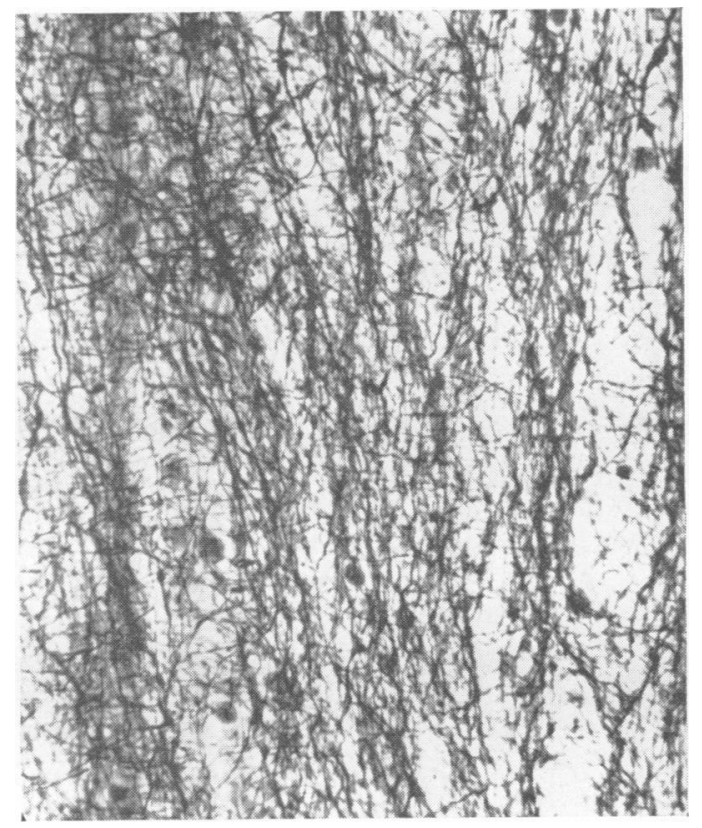

FIG. 4. Preserved axis cylinders in a fully demyelinated area of the temporal lobe. Gros-Bielschowsky $\times 325$. 

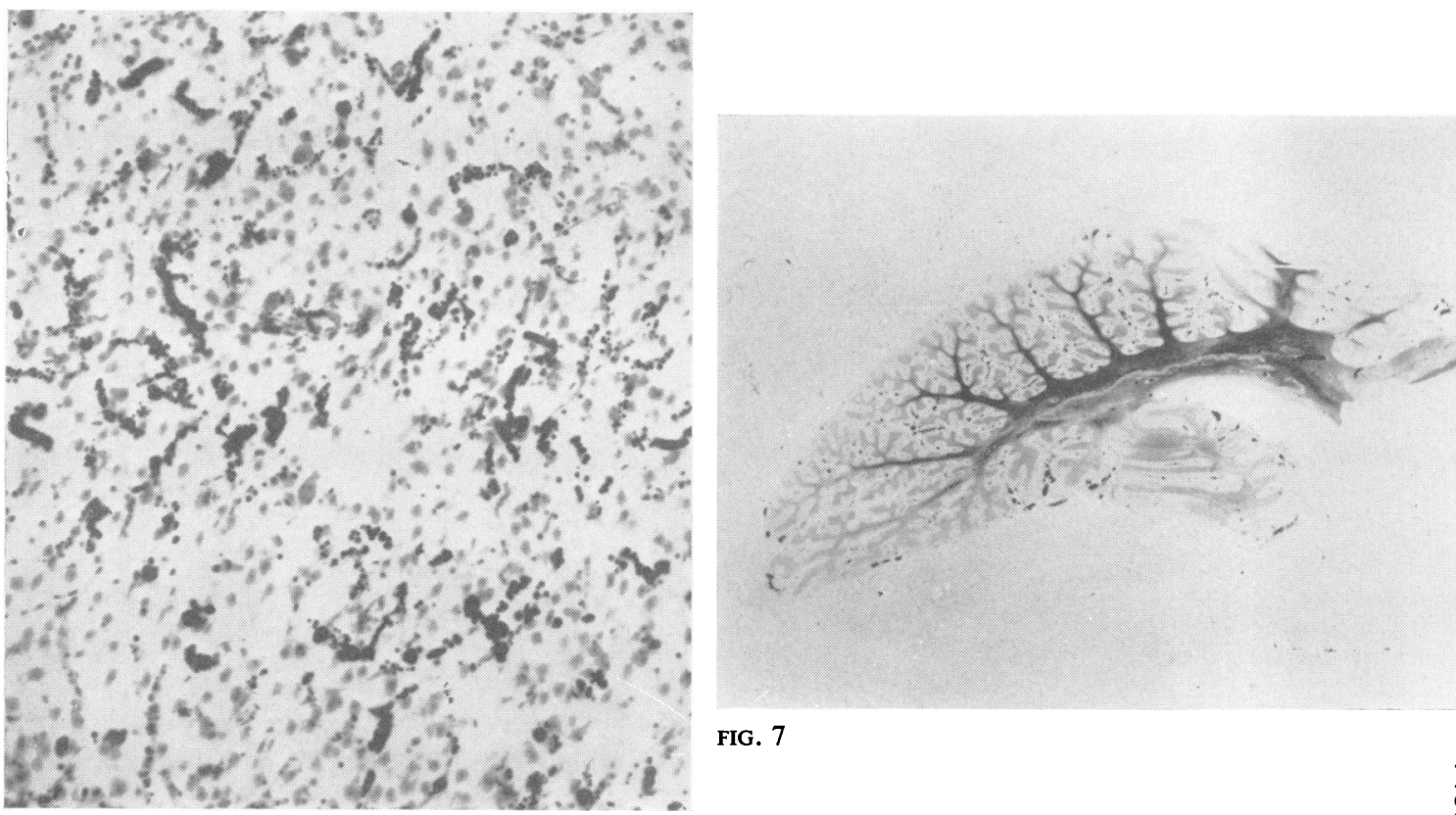

FIG. 7

FIG. 5

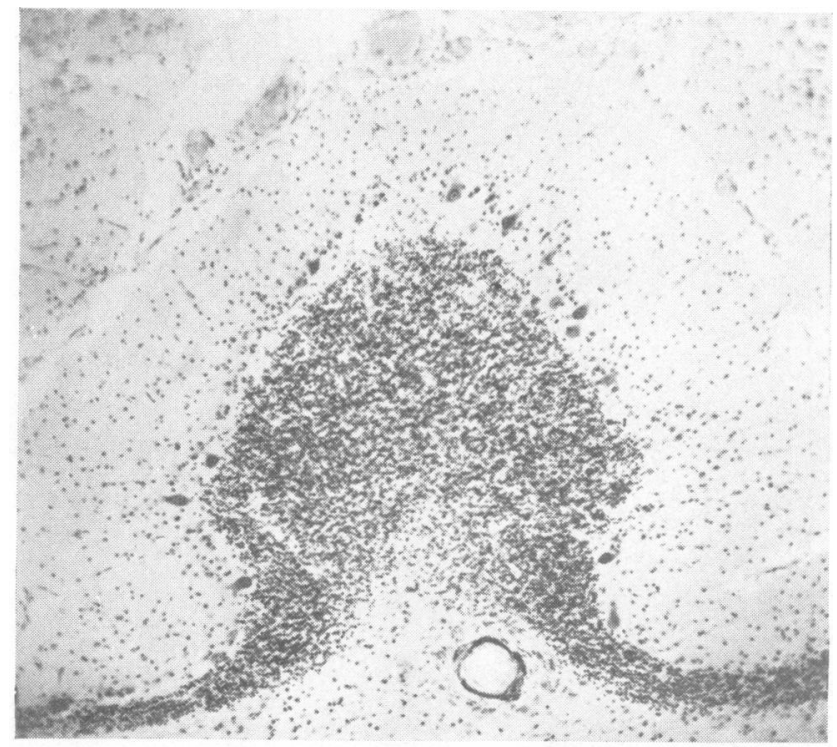

FIG. 5. Pericapillary calcification in the putamen. Carbol azure $\times 120$.

FIG. 6. Cerebellum showing loss of Purkinje cells slight rarefaction of the granular layer, and $a$ calcified vessel in the subcortical white matter. Carbol azure $\times 60$.

FIG. 7. Sagittal section of the lateral lobe of the cerebellum showing atrophy of the cerebral white matter $\times 1.6$. 


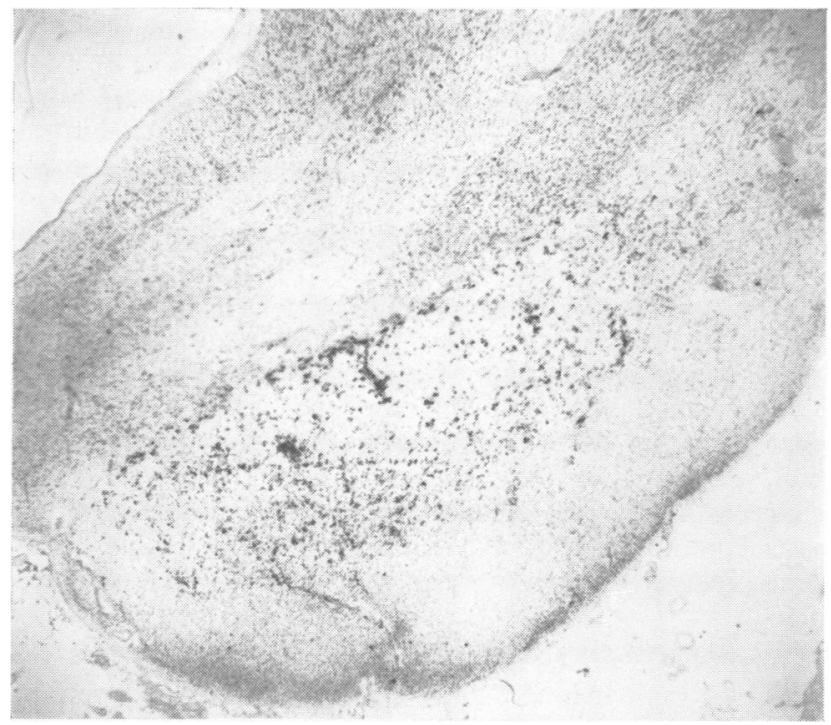

FIG. 8. Pigment is increased in the oral part of the red zone of the substantia nigra. Carbol azure $\times 12$.

FIG. 9. Patchy demyelination of the tegmentum of the mid-brain. Frozen. Kultschitsky-Pal $\times 2.8$.

FIG. 10. Pons. There is general atrophy with enlargement of the fourth ventricle. The transverse fibres are especially demyelinated. Heidenhain $\times 2.6$.

FIG. 8

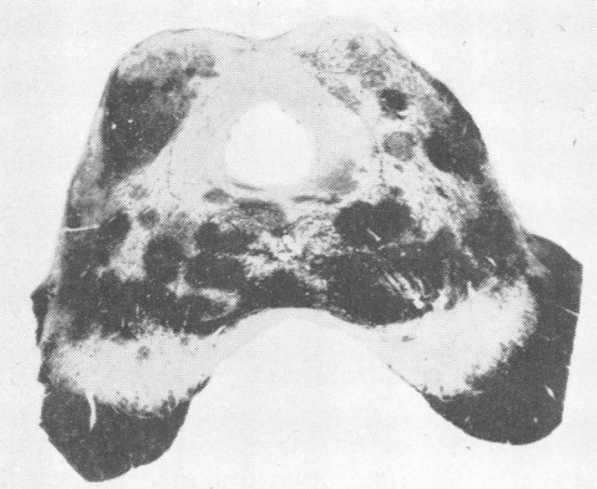

FIG. 9

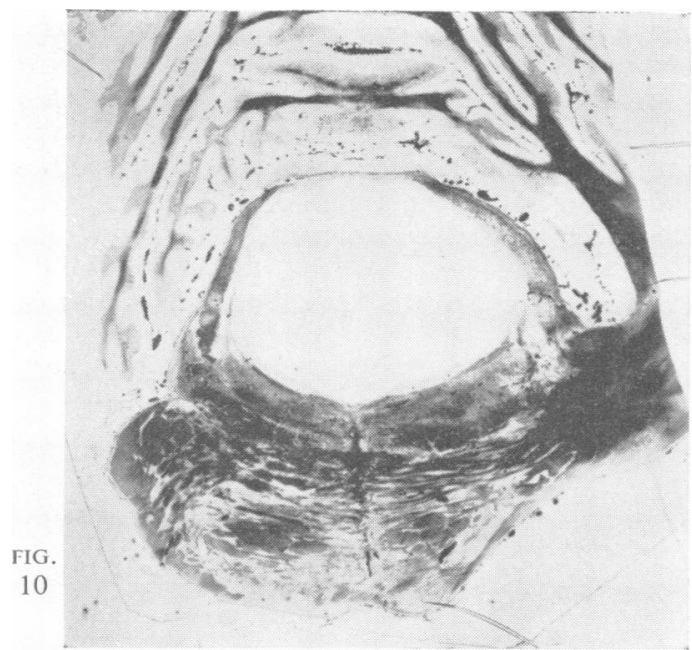

brains fixed in formalin. The lipid hexosamine and neuraminic acid, though raised above the average, were within normal limits. In the cerebral grey matter the most striking change was seen in the low neutral hexose. The normal sphingomyelin was surprising in view of the histological poverty of myelin sheaths but may have been due to the capricious action of fixation which, in our experience, particularly affects the estimation of the cholinecontaining phospholipids. This explanation is supported by the fact that thin-layer chromatography clearly showed a reduction in sphingomyelin both in cortex and white matter.

\section{DISCUSSION}

The evidence adduced by previous writers in favour of this condition being the result of an encephalitis in early life is mainly neuropathological, and it must be admitted that many of the features of the syndrome could be explained on that basis. The cerebral calcifications, granular ependymitis, meningeal fibrosis and patchy demyelination, while not in themselves specific of inflammatory change, are nevertheless possible sequelae of encephalitis. Moreover, in Hallervorden's case 3 normal development apparently ceased after a feverish illness beginning shortly after vaccination at the age of 18 months. Hallervorden also considered the demyelination to be essentially perivascular. For these reasons, most recent authors have followed Seitelberger (1954) in excluding these cases with calcifications from the category of Pelizaeus-Merzbacher disease or leucodystrophy. Yet in opposition to this 
view there is strong evidence of a genetic factor in some of the reported cases. Two of Hallervorden's patients in whose brains the 'inflammatory' stigmata were particularly well shown, were brother and sister. One of Jervis's patients had a microcephalic and mentally defective brother. The two brothers described clinically by Neill and Dingwall (1950) were microcephalic, and symmetrical basal gangliar and cerebellar calcifications were demonstrated radiographically. They had the same dwarfish and 'progerioid' appearance as our patient. Both brains have been examined in this laboratory and showed, in addition to massive putaminal and cerebellar 'brain stones', the same patchy demyelination, general shrinkage of the cerebral and cerebellar white matter, and preservation of axis cylinders, as in other reported examples of this syndrome (Norman, 1963). It may be added that in neither brain was the patchy loss of myelin related to blood vessels and, as in the present case, the picture could not be confused with the late results of perivenous encephalomyelitis. This genetic background makes it highly improbable that the syndrome is due to exogenous factors, though perhaps the possibility cannot be ruled out that this small group is not aetiologically homogeneous, despite the many clinical and pathological features shared in common.

The present sporadic example of this disorder resembles the familial cases in all respects except that the cerebral calcifications were not so massive. The excess of pigment in the substantia nigra and globus pallidus was also present in the case of Horanyi-Hechst and Meyer, and in the NeillDingwall siblings. Hallervorden also noted pallidal pigmentation in his familial cases. This latter phenomenon is usually considered characteristic of Hallervorden-Spatz disease, but it is a not infrequent finding in a variety of other conditions best classified in their own right (Meyer, 1963). Similarly, the pericapillary calcifications cannot be regarded as a specific disorder of metabolism since they are so commonly found in conditions of inflammatory, degenerative, or endocrine origin (Erbslöh and Bochnik, 1958).

There can be little doubt that the presence of these calcifications has in the past deflected attention from the most characteristic feature of this syndrome, namely, the demyelination. When the present case is considered from this point of view it falls without qualification into the second subgroup of sudanophil leucodystrophies as defined by Diezel, Fritsch, and Jakob (1965), namely, those with spotty (discontinuous) demyelination and variable amounts of myelin-breakdown products of exclusively orthochromatic type.

The chemical analysis of this brain did not show the unequivocally raised lipid hexosamine which is so often found in various forms of leucodystrophy, but the latter change is not necessarily present in all familial demyelinating diseases (Bargeton-Farkas and Edgar, 1964). For example, in the brothers described by Lüthy and Bischoff (1961) there was widespread patchy demyelination but no increase in the lipid hexosamine.

Certainly many authors would prefer to apply the name 'Pelizaeus-Merzbacher disease' to this chronic condition, but one of the merits of the classification used by Diezel et al. is that this eponym is reserved for cases closely similar to those described by the original authors and is not stretched to include other diverse clinical and genetic conditions which pathologically have only a remote resemblance to the classical cases.

\section{SUMMARY}

A male mental defective of dwarfish and progerioid appearance suffered from spastic paraparesis which had apparently developed in the early years of life. He died at the age of 22 years. Neuropathological examination showed a condition of micrencephaly with dilated ventricles, due mainly to a gross shrinkage of the white matter of the cerebral hemispheres, cerebellum, and brain-stem. In the white matter there was a patchy, discontinuous type of demyelination, the better preserved areas appearing as myelin islands set against a poverty of myelinated fibres The basal ganglia showed more diffuse demyelination. These changes were accompanied by a mild fibrous gliosis, small amounts of sudanophil lipid, and well-preserved axis cylinders. Calcification of capillaries and smaller blood vessels was present bilaterally in the putamina and in the cerebellum, and there was an increase in pigment in the globus pallidus and the red zone of the substantia nigra. Chemically the white matter showed a marked loss of myelin lipids and increased cholesterol ester. Reasons are given for classifying this condition as a form of sudanophil (orthochromatic) leucodystrophy, and not as the sequel of early encephalitis as has been previously supposed.

We are very grateful to Dr. Grace Woods for her clinical notes, to Dr. T. F. Draisey for the necropsy report, and to Dr. Norman Brown who sent us the brain for examination.

\section{REFERENCES}

Bargeton-Farkas, E., and Edgar, G. W. F. (1964). Anatomo-chemica studies on a case of congenital sudanophilic leucodystrophy. Acta neuropath. (Berl.), 3, 578-587.

Diezel, P. B., Fritsch, H., and Jakob, H. (1965). Leukodystrophie mit orthochromatischen Abbaustoffen. Ein Beitrag zur Pelizaeus-Merzbacherschen Krankheit. Virchows Arch. path. Anat., 338, 371-394. 
Erbslöh, F., and Bochnik, H. (1958). Symmetrische Pseudokalk-und Kalkablagerungen im Gehirn. In Handbach der speziellen pathologischen Anatomie und Histologie, Band 13, Teil 2, Bandteil B, edited by O. Lubarsch, F. Henke, and R. Rössle, pp. 1769-1809. Springer, Berlin.

Hallervorden, J. (1950). Úber diffuse symmetrische Kalkablagerungen bei einem Krankheitsbild mit Microcephalie und Meningoencephalitis. Arch. Psychiat. Nervenkr., 184, 579-600.

Horanyi-Hechst, B., and Meyer, A. (1939). Diffuse sclerosis with preserved myelin islands: a pathological report of a case, with a note on cerebral involvement in Raynaud's disease. $J$. ment. Sci., 85, 22-28.

Jervis, G. A. (1954). Microcephaly with extensive calcium deposits and demyelination. J. Neuropath. exp. Neurol., 13, 318-329.
Lüthy, F., and Bischoff, A. (1961). Die Pelizaeus-Merzbachersche Krankheit. Acta neuropath. (Berl.), 1, 113-134.

Meyer, A. (1963). In Greenfield's Neuropathology, 2nd ed., p. 412. Arnold, London.

Neill, C. A., and Dingwall, M. M. (1950). A syndrome resembling progeria: A review of two cases. Arch. Dis. Childh., 25, 213-221.

Norman, R. M. (1963). In Greenfield's Neuropathology, 2nd ed., p. 350. Arnold, London.

Seitelberger, F. (1954). Die Pelizaeus-Merzbachersche Krankheit. Wien. Z. Nervenheilk., 9, 228-289.

Tingey, A. H. (1959). The results of glycolipid analysis in certain types of lipidosis and leucodystrophy. J. Neurochem., 3, 230-237.

- , and Edgar, G. W. F. (1963). A contribution to the chemistry of the leucodystrophies. Ibid., 10, 817-823. 